Recibido: 7/10/2015

Aprobado versión definitiva: 25/11/2015

\title{
Estrategias de comercialización y marketing urbano: el producto Puerto Norte Rosario, Argentina
}

CINTIA BARENBOIM ${ }^{1}$ / GASPAR TOMINO²

\section{RESUMEN}

El objetivo es identificar las estrategias de comunicación y publicidad con que se abordan los públicos específicos del gran proyecto urbano de Puerto Norte, antiguamente predios del ferrocarril y el puerto. Se analiza también la dinámica del mercado inmobiliario, entre los años 2005 y 2014. La metodología se centra principalmente en el análisis de contenido de documentos escritos y gráficos. Además, se recurre a la modalidad interpretativa para realizar entrevistas semiestructuradas a actores claves. Los principales resultados evidencian que la comercialización se presenta de forma variada, en la que la oferta es restringida por los medios de comunicación a valores y representaciones simbólicas, entendiendo los proyectos como bienes de consumo.

Palabras claves: mercado inmobiliario, modelo de ciudad, acciones de comunicación, nueva centralidad, Rosario.

\footnotetext{
1 Doctora en Geografía de la Universidad de Buenos Aires. Docente de Planeamiento y Urbanismo de la Universidad del Rosario, Argentina. Afiliada a la Universidad Abierta Interamericana, Pellegrini 1614. Código postal (2000) Rosario. Correo electrónico: arq.barenboim@gmail.com.

2 Licenciado y Profesor Universitario en Comunicación Social. Docente de Socio- antropología de la Comunicación de la Universidad Nacional del Rosario, Argentina. . Afiliado a la Universidad Abierta Interamericana, Pellegrini 1614. Código postal (2000) Rosario. Correo electrónico: gaspartomino@hotmail.com.
} 


\section{MARKETING STRATEGIES AND URBAN MARKETING: PUERTO NORTE PRODUCT ROSARIO, ARGENTINA}

\section{ABSTRACT}

The aim is to identify communication strategies and advertising to specific audiences large urban project of Puerto Norte, formerly the premises of the railway and port addresses, also analyzing the dynamics of the housing market between 2005 and 2014.

The methodology focuses primarily on content analysis of written and graphic documents. In addition, we resort to the interpretive method for semistructured interviews with key actors.

The main results show that marketing is presented variously, where supply is restricted by the media values and symbolic representations, understanding projects as consumer goods.

Keywords: Property, city model, communication actions, new centrality, Rosario.

\section{Introducción}

Rosario es hoy en día una de las ciudades con mayor desarrollo económico del país. A partir del 2003, la ciudad experimentó un rápido crecimiento de la actividad económica motivada principalmente por la renta generada en el sector agropecuario. La falta de confianza en el sistema financiero determinó la inversión de estos beneficios extraordinarios en el sector de la industria de la construcción. La reactivación del mercado inmobiliario, junto con las nuevas normativas municipales, dio lugar a grandes transformaciones edilicias en toda la ciudad, principalmente en el área central, macrocentro y zona ribereña. También parte de la inversión se orientó a nuevos emprendimientos de carácter residencial e industrial en la periferia (Barenboim, 2013).

En este contexto, lo que se pretende registrar es el movimiento fundado hacia el interior de la ciudad, orientado a la densificación vertical y en algunos casos a la conservación del patrimonio situado en el proyecto de renovación 
urbana de Puerto Norte, antiguamente predios del ferrocarril y el puerto. Este constituye una nueva centralidad, definida claramente por Janoschka (2002) quien expresa que:

Las transformaciones urbanas no sólo implican nuevos desarrollos en espacios pequeños, sino también centralidades completamente nuevas por fuera del área tradicional. Estos puntos de concentración de provisión de servicios, superficie de oficinas y comercios son denominados EdgeCities donde las tradicionales fuerzas urbanas centrales no poseen una relación funcional con el núcleo urbano y se localizan en un nuevo lugar. (p.5)

La nueva centralidad Puerto Norte surge entonces como una necesidad frente al proceso de crecimiento urbano de la ciudad, ofreciendo una diversidad de usos residenciales, comerciales, oficinas y de entretenimiento, reduciendo las distancias y desplazamientos de los habitantes de la ciudad. Esto ha sido viable por la apertura de la ciudad al río mediante la generación de un nuevo frente urbano y el traslado del puerto al sur de la ciudad. También por dejar zonas vacantes para nuevos desarrollos, lo que permitió transformar la imagen de Rosario e impulsarlo aun futuro de progreso ${ }^{3}$.

La rivalidad y la competencia entre las ciudades es cada vez mayor en un mundo globalizado, en el que la puesta en valor de lo local, la innovación de las estrategias de comunicación y de publicidad, entre otras cuestiones, juegan un rol muy importante en la representación de los espacios urbanos. El presente artículo se centra en el funcionamiento del mercado inmobiliario y la continua valorización de Puerto Norte. Se identifican las estrategias de comunicación con que se abordan los públicos específicos, en el marco de un modelo de ciudad, durante la última década.

${ }^{3}$ La reconversión del antiguo puerto se establece con la gran operación público - privada denominada "Centro de Renovación Urbana Scalabrini Ortiz", llevada a cabo en dos fases. La primera fase comprende el Parque Scalabrini Ortiz, el Shopping Alto Rosario y el supermercado COTO inaugurados en 2004. La segunda fase define el proyecto de Puerto Norte a través de un plan especial que indica los trazados públicos, los espacios verdes y el esquema de densidades (Barenboim, 2014). 


\section{Estado de la cuestión}

Entre las investigaciones locales realizadas, se mencionan a continuación las que suponen una aproximación al tema, dado que ninguna incluye todas las variables. A modo de contexto general, Barenboim (2010) explica la evolución y desarrollo del mercado inmobiliario local, de comportamiento enormemente dinámico y que opera generalmente con gran libertad y sufre diversas variaciones. Particularmente, el proyecto urbano de Puerto Norte es tomado por Cuenya y su equipo a través de dos trabajos: en el primero investiga la movilización de plusvalías generadas particularmente entorno al primer sector, Unidad de Gestión Cinco (2009). El segundo, analiza distintas experiencias en Argentina (incluyendo a Rosario) de grandes proyectos urbanos en relación a los cambios que producen en la centralidad, los intereses dominantes y rentabilidad del suelo (2012). Posteriormente, Barenboim (2014) describe la evolución de la costa central y su vinculación con el gran proyecto urbano de Puerto Norte.

Desde el punto de vista comunicacional, no abundan estudios en profundidad acerca de las estrategias utilizadas por los agentes de comercialización. Se pueden enumerar algunos casos (no siempre específicos sobre la zona a estudiar) como el llevado adelante por Ramírez Bayardi (2012) acerca de las comunicaciones externas de BauenPilay. El autor Ortolá Martínez (2013) aborda aspectos generales de sus experiencias como asesor en desarrollos inmobiliarios en Ciudad Rivera. Otro caso de interés lo constituyen las campañas de Bartolomé - Marketing y Comunicación realizadas a pedido de la Corporación de Empresas Inmobiliarias de Rosario (CEIR) y la Asociación de Empresarios de la Vivienda (AEV) con el objetivo de revalorizar la inversión en ladrillos en tiempos de crisis (2009) y que involucró a los proyectos urbanísticos de Puerto Norte. 


\section{Metodología utilizada}

La investigación se centra principalmente en un abordaje analítico, a partir del análisis de contenido de documentos escritos y gráficos como ser:

- No oficiales: trabajos de investigación, artículos periodísticos de los diarios, revistas locales y publicidades de inmobiliarias en revista Mercado Inmobiliario, diarios mencionados y en la web.

- Oficiales, Instrumentos de reordenamiento urbanístico: Plan Urbano Rosario 2007 - 2017 (2011). Ord. Básica № 7.892/05 2da Fase del Centro de Renovación Urbana Scalabrini Ortiz-Puerto Norte y complementarias de cada sector: Ord. N ${ }^{\circ} 8.320 / 08$ Unidades de Gestión 1 y 6 , Ord. № 8.237/08 Unidad de Gestión 2, Ord. № 8.297/08 Unidad de Gestión 4, Ord. № 7.893/05 Unidad de Gestión 5.

Relevamiento de la oferta de comercialización de inmuebles en las siete unidades de gestión publicados por las inmobiliarias y el diario La Capital.

Además, se recurrirá a la modalidad interpretativa para la realización de entrevistas semi- estructuradas a funcionarios municipales y actores sociales, en torno a dos ejes de producción - uso del espacio y estrategias de comunicación. El propósito es completar la información que no se halla en los documentos.

\section{Características del mercado inmobiliario}

El mercado de tierras es un elemento fundamental en la configuración de las ciudades, siendo la tierra el soporte y materia prima del desarrollo urbano. Este es un fenómeno complejo en el que intervienen diversos factores económicos, políticos y sociales. A ello se suma el accionar de actores con distintas racionalidades e intereses. Se entiende por mercado, según Harvey (2007), a cualquier arreglo mediante el cual vendedores y compradores se unen para determinar un precio en el cual los bienes pueden ser intercambiados. En el caso del suelo o inmueble, representa un término abstracto que engloba el conjunto de transacciones que se realizan con el bien. 
En la cuestión de Puerto Norte el proceso de ocupación del suelo es intensivo, influyendo porcentualmente en la densificación de la ciudad. En 2007 el $10 \%$ aproximadamente de la superficie edificada de permisos de obra nueva corresponden a Puerto Norte (superficie total en Rosario: $898.787 \mathrm{~m}^{2}$ ). Este registro de la edificación fue único y ha decrecido en los años siguientes. Al mismo tiempo, la evolución de la población es ascendente, estimando que residirán cuando el proyecto esté concluido, según Martínez (2014): “... aproximadamente 30.000 habitantes, sin considerar el flujo de personas que va por trabajo u otra actividad (recreación, comercio, etc.)" ${ }^{\prime 4}$. El dinamismo edilicio y poblacional es significativo en otras áreas de Rosario sin embargo aquí se reconoce la gran magnitud que ofrece la transformación urbana.

La nueva centralidad permite la proximidad de usos y mayor densidad edilicia, al mismo tiempo que favorece los intercambios con el espacio público. Las siete Unidades de Gestión (UG) que lo componen poseen diversas situaciones dominiales (propiedad pública y propiedad privada), normativas y estados de construcción, iniciándose en el año 2005, no estando concluidas en la actualidad (ver Plano 1). A continuación se detalla cada una:

- UG1: el predio de 8,4 has. perteneciente a Servicios Portuarios S. A. contempla un conjunto residencial y comercial llamado Metra iniciado en 2014.

- UG2 - Sector 1: el terreno de una superficie de 2,1 has. adquirido por la empresa TGLT para desarrollar el emprendimiento residencial Forum entre 2008 y 2013.

- UG2 - Sector 2: la superficie es de 2,1 has., propiedad de Ingeconser S.A., propone viviendas, oficinas, hotel y centro de convenciones denominado Ciudad Ribera, iniciado en 2009 y finalizado en 2014.

\footnotetext{
4 Entrevista realizada a la Coordinadora del Programa de Equilibrios Centro Periferia de la
} Secretaria de Planeamiento Arq. Cecilia Martínez. Rosario, 17/09/14. 
- UG4: la superficie de 2,3 has. de distintos inversores locales para uso residencial todavía no ha comenzado las obras.

- UG5: el sector de 1,7 has. desarrollado por Inversiones y Mandatos S. A. está compuesto de tres unidades: conjuntos residenciales Dolfínes Guaraní y Torre Embarcadero y edificio Nordlink (destinado a oficinas premium), iniciado en 2005 e inaugurado en 2010.

- UG6: el predio de 2,5 has. perteneciente a Servicios Portuarios S. A. proyecta el complejo Maui para viviendas y un hotel internacional, iniciado en 2009.

- UG3 y 7: los terrenos nacionales del Administrador de Infraestructuras Ferroviarias (ADIF), superficies de 36,2 has. y 20,7 has., no han iniciado aún las obras.

- M. 407: el sector comprende una superficie de 5 has., localizado contiguo al Shopping Alto Rosario, corresponde a dos propietarios locales: Fundar y Rosental. Los Condominios del Alto, iniciados en el 2007, se destinan a hotel, comercios y vivienda 5 .

A pesar del trascendental impacto edilicio que provoca el gran proyecto urbano, hasta el año 2014 solamente se ha edificado el $20 \%$ de la superficie total, considerando que estará completo dentro de diez años. La delimitación como el destino también varían, siendo la actividad predominante la residencial (Barenboim, 2014).

\footnotetext{
5 En el año 2006, a las siete Unidades de Gestión que componen el Plan Especial Puerto Norte se incorpora la Manzana 407, anteriormente incluida en la Fase 1 del Centro de Renovación Urbana Scalabrini Ortiz.
} 


\section{Figura 1. Unidades de Gestión de Puerto Norte Rosario}

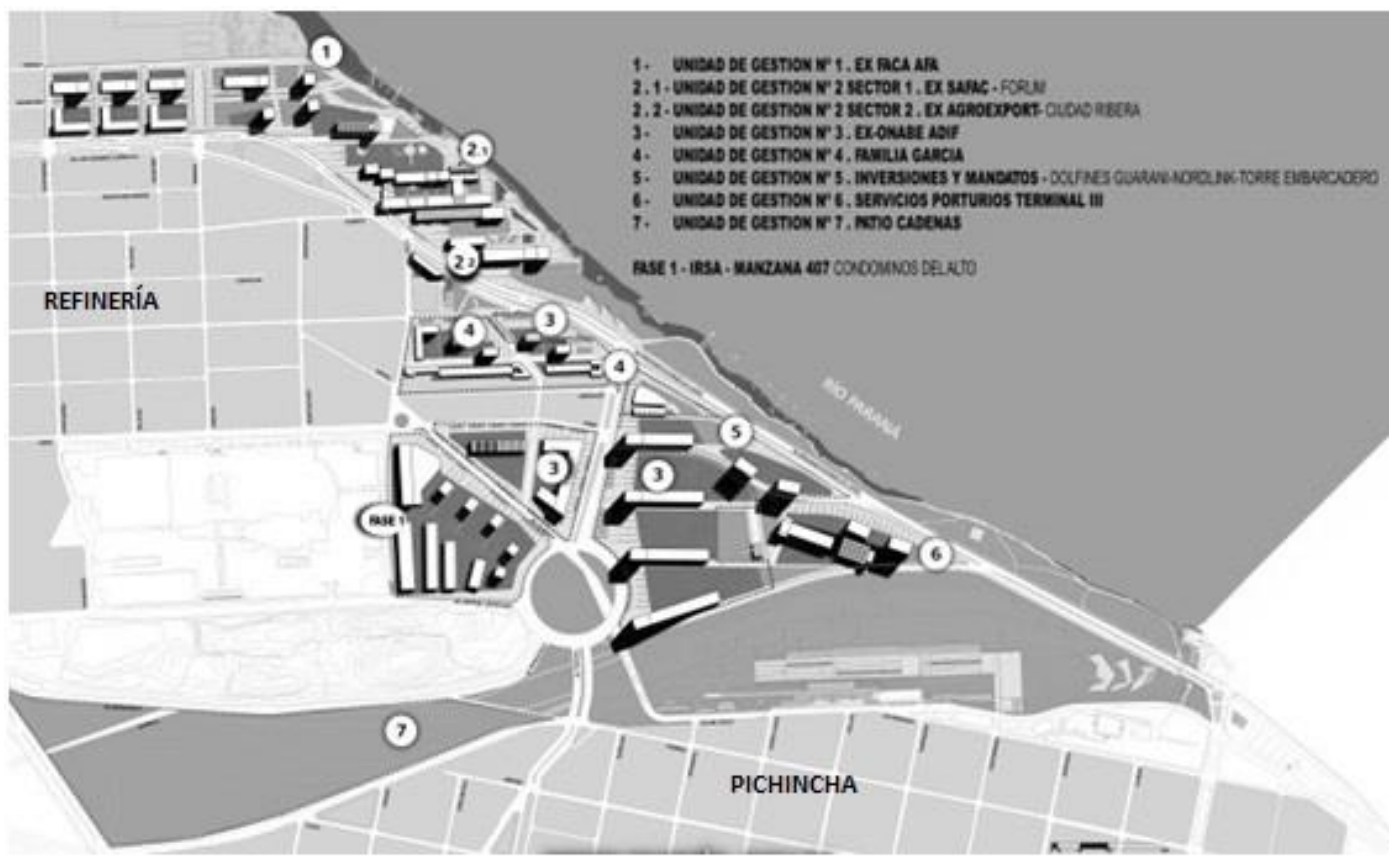

Fuente: Dirección General del Plan Director, 2011.

La dinámica del mercado en Puerto Norte no ha sido constante identificando tres momentos claves, según Grandinetti (2015):

Un primer momento (2005-2008) donde hay un alto impacto de ventas orientado a unidades de grandes dimensiones y oficinas premium. Las Dolfínes Guaraní, Nordlink y Embarcadero (UG5), pertenecientes a una desarrolladora rosarina, ya eran una marca chequeada en la ciudad y generaba mucha confianza mientras que Forum y Ciudad Ribera (UG2), de capitales externos (Buenos Aires y España respectivamente), tuvieron que asociarse a capitales e inmobiliarias locales para poder completar sus ventas. Luego, un segundo momento (2009 - 2011) donde desciende la venta de alta gama y el mercado se empieza a fraccionar, ofreciendo unidades residenciales más pequeñas como los Condominios del Alto II y III y locales comerciales para la renta. Por último, (2012-2014) debido a un mal diagnóstico sobre el cepo bancario, que generó un mensaje negativo sobre el mismo sector, las decisiones se tornan más largas. La crisis estaba en la oferta y no en la demanda, que continúa orientada a las unidades más pequeñas, introduciéndose en el mercado Metra (UG1) ${ }^{6}$.

6 Entrevista realizada al presidente de la Federación Inmobiliaria Argentina y Colegio de Corredores Inmobiliarios de Santa Fe Arq. Javier Grandinetti. Rosario, 02/04/15. 
Las operaciones tomaron más tiempo del esperado, atribuible esto a una abundante oferta generada por el incremento de inmuebles dada la creciente actividad de la construcción en la ciudad. Hasta el momento, según Grandinetti (2015), Puerto Norte “... Ileva un nivel de venta aproximadamente del $50 \%$ de las Unidades: Dolfínes y Ciudad Ribera (100\%), Forum (70 \%), Maui (50\%) y Metra (30\%)". ${ }^{7}$ La demanda también creció a partir de la reactivación del sector, dado que se elige como lugar de vivienda y trabajo, de inversión o resguardo del capital. Esta última modalidad, expresa Barenboim (2015), se refiere a la seguridad que otorga destinar el excedente del capital en el mercado inmobiliario, sin necesariamente buscar algo a cambio, pudiendo la propiedad estar desocupada, en alquiler o venta. Las unidades se pueden revender, antes o después de la posesión, debiendo transcurrir como mínimo doce meses desde la firma del boleto de compra-venta. Al respecto, Decima (2012, p.2) señala que: “... las marcas de estos proyectos, la trayectoria del desarrollista, han favorecido estas decisiones de inversión. Si el inmueble es de alta gama, tiene marca, respaldo comercial y profesional, sigue su desempeño de ventas de manera continua".

En suma, la oferta y la demanda de los inmuebles suelen ser constantes en este segmento premium, siendo el menos sensible a las contingencias macroeconómicas y de mayor valorización del mercado.

\section{Comercialización según sub-mercado}

La comercialización de los diferentes bienes se presenta en forma variada según los distintos usos que ofrece Puerto Norte: los departamentos pequeños y locales comerciales es alta, en los departamentos grandes es intermedia y en las oficinas tiene otro ritmo. Asimismo, los sub-mercados no funcionan aisladamente sino que se articulan entre sí, tanto en relación a los agentes como a los productos, habiendo generalmente en un mismo predio distintas actividades (Barenboim, 2015). A continuación se detalla cada uno de ellos:

7 Ídem 6. 
Mercado Residencial: cuenta con la construcción de torres de alta gama, habiendo una gran división entre los espacios para ser habitados, los amenities y espacios comunes. La proporción de estos últimos en relación a la vivienda es lo que encarece, y a la vez aporta la diferencia con el resto de los edificios. Las superficies de los departamentos varían entre $30 \mathrm{~m}^{2}$ y $300 \mathrm{~m}^{2}$, desde monoambientes a cuatro dormitorios. Las unidades más caras están en los pisos superiores y las más económicas en los inferiores. Además, se identifican valores desiguales según la Unidad de Gestión; las más económicas y con mayor financiamiento son las UG1. Metra y M.407. Condominios del Alto (2.800 y 2.913 $\left.\mathrm{U} \$ \mathrm{~s} / \mathrm{m}^{2}\right)$. Mientras, los más costosos son las UG5. Dolfínes Guaraní Embarcadero y UG6. Maui (3.920 y $4.100 \mathrm{U} \$ \mathrm{~s} / \mathrm{m}^{2}$ ), si tomamos los departamentos nuevos de dos dormitorios para el año 2014 (Barenboim, 2015). El valor promedio de los departamentos se triplicó desde el lanzamiento a la venta en el año 2006 hasta el 2014. Los edificios se entregan diferidos en el tiempo permitiendo acomodar a cada propietario un plan de cuotas funcionales a sus necesidades ${ }^{8}$.

Mercado Comercial: se refiere a los locales que se localizan en las plantas bajas de algunas de las torres residenciales. Estos facilitan las comodidades a los residentes como también atraen a otras personas por fuera del emprendimiento. Algunas cadenas gastronómicas eligen poner una sucursal allí (Club de la Milanesa, Queens, entre otros). Las superficies varían entre $50 \mathrm{~m}^{2}$ y $250 \mathrm{~m}^{2}$. Los precios son muy variados dependiendo de su localización, la Unidad de Gestión y las dimensiones del local. Generalmente, se adquieren bajo la modalidad de alquiler. También la propuesta de alojamientos de alta categoría comienza a instalarse en Puerto Norte donde se encuentran tres hoteles cinco estrellas en Ciudad Rivera, Maui (proyectado) y Condominios del Alto.

\footnotetext{
${ }^{8}$ Las modalidades de pago en los fideicomisos requiere un anticipo que varía de acuerdo a la proximidad de la entrega del departamento y cada Unidad de Gestión (entre 15 y 30 \%). Luego se paga en porcentajes el saldo; previo a la posesión a través de la "cuota espera" (que es más baja) y en algunos casos posteriores a la entrega "cuota post - posesión" (más alta).
} 
Mercado de oficinas: son edificios destinados a oficinas premium para empresas, ejecutados bajo reglas internacionales a través de una nueva distribución, prestaciones y entorno motivador (Ciudad Ribera, Forum, Nordlink). La presencia de algunas de las firmas más importantes del país vinculadas a servicios, sector agropecuario, entre otros (Globlant, Sidersa, Zeni, AGD, banco Santander Río, etc.), están presentes. Rosario carecía de oficinas de grandes dimensiones, para compra o alquiler en áreas centrales, ampliando estos productos notablemente la oferta del sector. Las superficies varían desde unidades de aproximadamente 36 hasta $360 \mathrm{~m}^{2}$, los precios son similares al de los departamentos y pueden adquirirse en un plan de cuotas al igual que en el caso de los departamentos.

Mercado de entretenimiento: Rosario es sede de grandes eventos de alcance nacional e internacional contando en el sector con el Centro de Convenciones Puerto Norte (Ciudad Ribera), espacio de alta gama para eventos. También cuenta con el Shopping Alto Rosario que además de contar con otro Centro de Eventos denominado Metropolitano, locales y complejo de cines, posee dos Museos (Ferroviario y de los Niños). Los nuevos espacios públicos favorecen el intercambio con los usos anteriormente señalados y comprenden: Parque de la Estación, las Vías y Arenera; plazas Estación Embarcadero, Mutualismo y Ciudad Ribera, las ramblas sobre la barranca y las principales avenidas. 


\section{Figuras 2 y 3.Conjuntos residenciales Dolfínes Guaraní -Embarcadero y edificio de oficinas Nordlink. Complejo residencial - comercial Ciudad Ribera y plaza pública en Puerto Norte Rosario.}
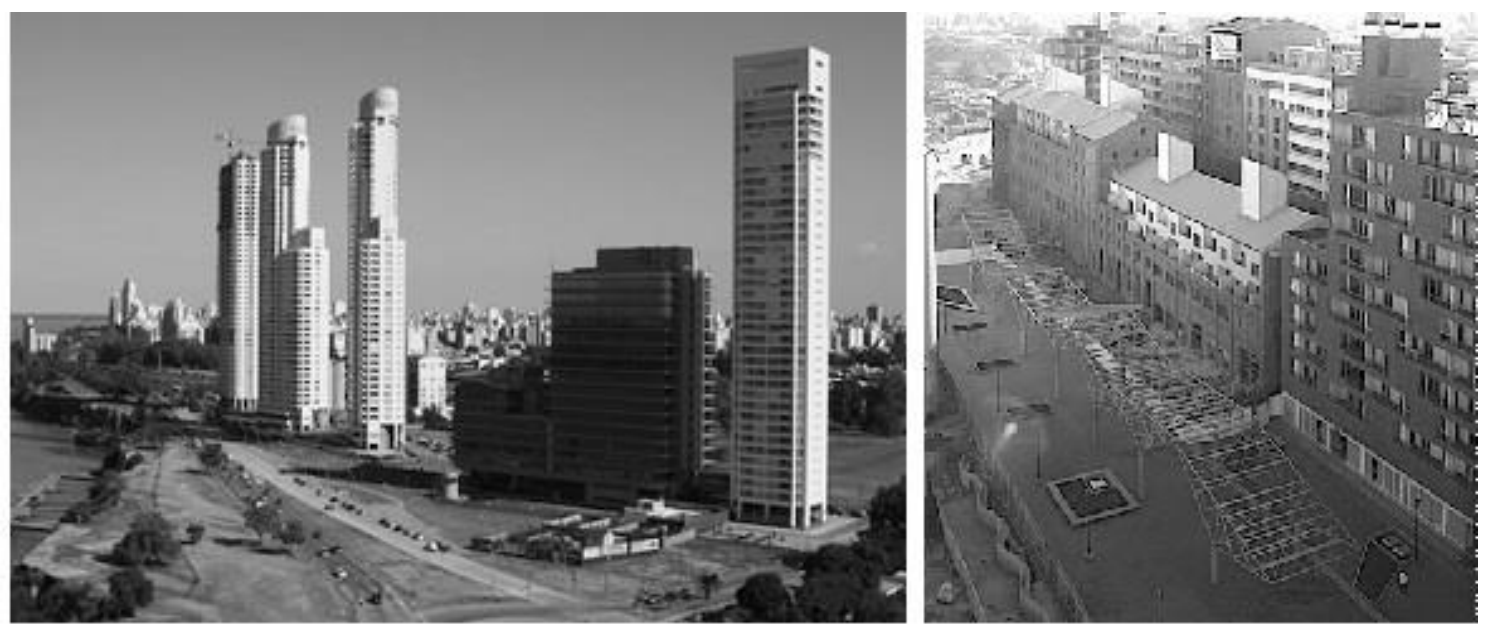

Fuente: Sica, 2014.

A partir de la descripción de las diferentes categorías de inmuebles, es decir de sub-mercados, se observa que si bien hay una oferta variada de usos (residencial, comercial, de oficinas y entretenimiento), aún hay equipamientos que no se consideraron para absorber el gran volumen de población que residirá y trabajará en el lugar. Por ejemplo no se han pensado espacios destinados a dar servicios especiales como ser educativos (jardines de niños, escuela primarias, secundarias y terciarias) o ampliar el área salud (clínicas y hospitales), contando solo con algunos consultorios en ciertas Unidades de Gestión. De la misma forma, se menciona que no se ha apreciado en el gran proyecto, la histórica demanda de viviendas para las clases medias-bajas de la ciudad.

$\mathrm{Si}$ se compara la inversión en inmuebles realizada en Rosario y especialmente en Puerto Norte, esta ha otorgado una rentabilidad atractiva (e inclusive superior a la financiera) durante los últimos años. Al respecto, Grandinetti (2015) expresa que

... las perspectivas del mercado en este sector están ligadas a lo que pase en la ciudad. En la medida que se continúe incorporando el frente del río y creciendo la ciudad, el segmento se amplía, los excedentes crecen en calidad de inversión e irán completando todas las unidades (...). El número de departamentos 
desocupados estimo será muy bajo, dado que no aportan dinero e inclusive resultan costosos por el alto pago de las expensas ${ }^{9}$.

\section{Actores involucrados en el proceso de la construcción}

Dado que los emprendimientos desarrollados en Puerto Norte son de gran envergadura, el análisis involucra en el proceso productivo a diversos y mayores agentes que en el resto de la ciudad. El Estado local tuvo un rol trascendental en dicho sector. Por un lado, las distintas reparticiones que componen la Municipalidad de Rosario donde se planifica y gestiona el proyecto urbano (Secretaría de Planeamiento, Secretaría de Obras Públicas, Programa de Equilibrio Centro - Periferia, Programa de Preservación y Rehabilitación del Patrimonio, Dirección de Diseño de la Vía Pública y Equipamiento Comunitario) y por el otro, el Consejo Municipal, en el que se controlan y aprueban las ordenanzas de los planes especiales y de detalle.

Los propietarios-desarrolladores de la tierra son agentes públicos como ser el ADIF (UG3 y 7) o privados extranjeros Servicios Portuarios, TGLT Real State e Inversiones Mandatos S.A. (UG1. Metra, UG2. Ciudad Ribera y Forum, UG5. Dolfínes Guaraní y UG6. Maui) o locales como Fundar, Rosental, Familia García y otros (UG4. García y M.407. Condominios del Alto). Los prestigiosos estudios de arquitectura son contratados por los desarrolladores para el diseño de las obras (Fernández Prieto, Solsona, Berman, Caballero, Pantoroto, Montan y Ferri). Asimismo, la venta de las Unidades de Gestión la realizan los propios desarrolladores, asociándose en algunos casos con inmobiliarias locales (Lamelas, Beltran, Furigo, etc.), teniendo importantes showrooms en el lugar.

Por último, los públicos que se intenta captar se dividen según los proyectos realizados entre: clase social media (UG1. Metra y M.407 Condominios del Alto), media-alta (UG2. Ciudad Ribera y Forum) y alta (UG5. Dolfínes Guaraní y UG6. Maui). Cabe señalar, que en el sector se encuentran sesenta familias de bajos recursos (UG4), que serán relocalizadas por los agentes privados en otro sector de la ciudad. Este ha sido el único caso de desplazamiento de la población por el

\footnotetext{
9 Ídem 6.
} 
gran proyecto inmobiliario, dado que Puerto Norte se realiza en los terrenos pertenecientes al ferrocarril y el puerto que se mantuvieron desocupados y vacantes de uso. Sin embargo, vale la pena mencionar lo que Martinis (2011) plantea sobre que este proceso: lentamente va dejando traslucir la fragmentación de los territorios produciendo una cierta segregación social en la que el Estado induce sucesivamente a través de sus políticas urbanas desplazamiento hacia las zonas menos favorecidas de la ciudad.

\section{Discursos para la promoción de las viviendas}

Los conjuntos urbanos que se promocionan en el área de Puerto Norte son fruto de un proyecto que pone de manifiesto un tipo de ciudad que surge a partir de un plan destinado claramente a dinamizar el mercado inmobiliario rosarino. Esto coloca en primer plano un modelo de ciudad que habilita una trasformación urbana donde el discurso se propone vender viviendas a compradores (receptores) a partir de dispositivos propios de la comunicación masiva. Así, la oferta inmobiliaria del área maneja diferentes dispositivos publicitarios que pueden ser claramente identificados, más aún cuando se trata de viviendas o unidades que por su ubicación y por ser parte de emprendimientos en gran escala, marcan claras estrategias de comercialización en soportes comunicacionales específicos. Esto claramente tiene que ver también con públicos objetivo que en ningún caso incluyen a sectores bajos, porque los bienes comercializados por los desarrolladores no incluyen la denominada "vivienda social" que está contemplada en el master plan.

Si partimos de la idea de que la publicidad $^{10}$ es una técnica de comunicación masiva destinada a difundir mensajes a través de diversos medios con el fin de persuadir a un grupo establecido de antemano para que consuma, es comunicación impersonal. Esta va dirigida a toda una masa de perceptores y

10 Por su parte, Ignacio Rodríguez define la publicidad como el "proceso específico de comunicación que, de un modo impersonal, remunerado y controlado, utiliza los medios masivos para dar a conocer su producto, servicio, idea o institución. Su primer objetivo es el de informar, dar a conocer; y el segundo consiste en influir en los comportamientos" (Ortega Carrillo y otros, 2011, p. 104). 
espera que estos asuman una función pasiva y se conviertan en consumidores (Mejía, 2009). Incluso podemos establecer algunos patrones comunes en las estrategias comunicacionales utilizadas por los grandes desarrolladores de Puerto Norte. Aun así, no podemos soslayar las visiones más contemporáneas que indican que hoy en día la publicidad estaría más cerca de ser considerada como un fenómeno más social y multidisciplinar en el que intervienen no solo componentes de carácter comercial sino todo aquello relacionado con la cultura, las formas de vida, la ideología, las actitudes y comportamientos, las tendencias (Hellín Ortuño y Fernández Rincón, 2014, p. 7).

Los discursos para la promoción de unidades hacen hincapié en diferentes campos semánticos en los que aparecen aspectos como el tiempo y el espacio ("Lo imposible se consigue en cuotas en pesos a diez años en Puerto Norte" en Metra), con lo cual se escenifica y "concretiza" una clara visión de los proyectos. El poder denotativo que se infiere de los mensajes utilizados deja claras marcas en cuanto a lo "evidente" de las propuestas en tanto no dejan dudas acerca de las condiciones físicas y materiales que ofrecen los bienes puestos a consideración de los públicos. La carga connotativa torna más atractivos los mensajes al actuar sobre los aspectos valorativos que hacen a los intereses de los posibles compradores de las unidades publicitadas.

Por otra parte, se apela a una construcción de identidad en cuanto a modelos relativos al ser o pertenecer si se compra lo que se ofrece ("Sentirse de viaje sin salir de su casa es el espíritu de este proyecto" en Maui). También son ostensibles los motivos y valores a los que se apunta en las construcciones discursivas en las que se intenta satisfacer necesidades y expectativas específicas de los potenciales compradores ("La comodidad de una casa, la practicidad de un departamento y la seguridad de un barrio privado" en los Condominios del Alto). Mejía Escalante (2009) señala diferentes elementos de promoción para el tipo de publicidad que analizamos: 
- Los logotipos de los emprendimientos, que aluden a sectores reconocidos de la ciudad y su emplazamiento en un ámbito ribereño (Maui representa dos tablas de surf en su logo y señala "La mística del río y el espíritu del mar" como eje central de su proyecto).

- Esquemas de localización de los conjuntos habitacionales que combinan buena ubicación, valorización y cercanía a todo. Condominios del Alto destaca: "Cada día son más los que eligen vivir cerca del río, cerca del centro, en medio de un paisaje urbano diferente".

- Simulación del conjunto residencial sin más edificaciones a su alrededor (las imágenes de Maui son quizá las más elocuentes en este aspecto).

- Los planos que exhiben la distribución y amueblamiento, donde se muestra su versatilidad y resolución como espacio ideal para habitar; un ejemplo prototípico en los tours virtuales de Torre Barranca, en Ciudad Ribera.

- Comodidades y equipamientos y los usos que la unidad dice poseer: amenities, recreación, espacios de socialización, seguridad, cercanía. Forum propone $10.300 \mathrm{~m}^{2}$ de jardines, piscina cubierta climatizada y piscina descubierta con solárium, parque de juegos infantiles, piscina con cascada y guardería infantil, sala de relax, sauna, gimnasio y vestuarios; canchas de tenis, guardería náutica, parrilleros; S.U.M. con terraza panorámica, bussines center, bauleras, lavadero, vigilancia central las 24 horas.

- La pareja o núcleo familiar como grupo de quienes habitan en unidad cerrada. "El lugar para vivir"; "Estamos comercializando el proyecto que cambiará la forma de vivir en Rosario", "El primer Distrito Planificado de Rosario que ofrece un verdadero cambio en la calidad de vida de sus habitantes", rezan los mensajes de Ciudad Ribera, marcando énfasis en los beneficios de vivir en un conjunto urbano que lo tiene todo.

Si intentamos un análisis interpretativo de la discursividad que manejan los promotores inmobiliarios en torno a tópicos como "seguridad de barrio privado, acceso alo imposible, sentirse de viaje, paisaje urbano diferente, jerarquía, el mejor lugar para vivir", se evidencia que estos mensajes tienden hacia la 
segregación social (dicho de otro modo: piensan una ciudad para pocos) y al consumismo como mecanismo para generar procesos particulares de identidad de los individuos (que los publicistas ubican en el segmento $A B C$ ). Las estrategias se apartan también del discurso que señala una planificación integral en: “... los emprendimientos privados de gran escala a los efectos de inducir un proceso de integración social, incorporando en una misma zona proyectos de vivienda para distintos sectores sociales" (Plan Urbano Rosario, 2011, p.59). Contrariamente, se propone un "barrio" nuevo creando una unidad aislada y homogénea, a partir de un proyecto que pone el valor del suelo urbano a costa de transformarlo en una suerte de "gueto premium", dejando de lado que (al menos en los papeles) el área contará con habitantes que no pertenecen a los sectores destinatarios de los mensajes postulados por las publicidades y avisos.

\section{Soportes publicitarios y acciones de comunicación}

Los soportes publicitarios que se utilizan (vallas, volantes, carteles, revistas de oferta inmobiliaria, showrooms) anuncian comodidades, áreas de esparcimiento dentro de las unidades, conectividad con los puntos neurálgicos de la ciudad, cercanía a áreas comerciales y formas de pago/facilidades/financiación de acuerdo al tipo de unidad en venta. Entre las acciones de comunicación que apuntan a optimizar las estrategias comerciales, el email marketing y la publicidad on-line parecen ser las preferidas por el sector. El email marketing es la acción más implementada por los desarrolladores, permitiendo alcanzar targets específicos en forma personalizada, con información que llega en forma directa a la bandeja de entrada del potencial comprador. Las notas de prensa son un fuerte complemento, junto a la publicidad en vía pública, radio y TV que le siguen en importancia; mientras, las redes sociales y la realización de eventos quedan en un tercer rango de actividad/frecuencia.

La publicidad gráfica sigue siendo elegida por los desarrolladores, ya que se sigue considerando como positivo su impacto en el paisaje urbano, a la vez que otorga amplia cobertura a las campañas. 
- UG1. Metra: apunta a un público de clase media, jóvenes profesionales y parejas que buscan acceder a su primer departamento. La estrategia aquí se centra en el ofrecimiento de mayor cantidad de cuotas en el pago (120 cuotas, hasta diez años de plazo para su cancelación). La frecuencia de aparición en páginas web es alta (semanal). Una acción fuerte del desarrollador se centra en el amplio showroom donde se atiende a los interesados. El slogan central es "lo imposible se consigue en cuotas", claro indicio de la intención de captar a sectores más amplios de consumidores, desde el segmento de clase media típica a la media-alta."Te ofrecemos un plan de cuotas funcional a tus necesidades", promete el desarrollador desde su perfil en Facebook.

- UG2. Forum: este emprendimiento se enfoca a un consumidor de alto poder adquisitivo, familias, parejas, profesionales. Las publicidades de Forum en las páginas de diferentes inmobiliarias suelen mostrar parejas en ambientes propios de los edificios del complejo (solárium, gimnasios, salas de relax, etc.) en clara alusión al estilo de vida suscripto y ponen el acento en imágenes que recuperan el esplendor arquitectónico que descansaba sobre los cimientos de la antigua Maltería. TGLT es el desarrollador que promociona también otros emprendimientos en Buenos Aires, Punta del Este, todos orientados a segmentos superiores de consumidores, a excepción de Metra.

- UG2. Ciudad Ribera: de modo similar a Forum, el target de este desarrollo es un consumidor de alto poder adquisitivo (familias, parejas, profesionales). Como reza el slogan "primer Distrito Planificado de Rosario que ofrece un verdadero cambio en la calidad de vida de sus habitantes". Uno de sus estandartes publicitarios es la Torre Barranca en tanto única construcción de altura sobre la propia barranca del río Paraná, con vistas panorámicas de 360 grados, para "sentir el río y la ciudad desde un lugar único". Llama la atención la construcción del mensaje donde se lanza el edificio Mirador Parque con el slogan "Ciudad Ribera a tu alcance", seguido 
de la frase "departamentos premium frente al río"; esto deja en claro quién es el destinatario del anuncio.

- UG5. Torres Dolfínes Guaraní, Nordlink y Embarcadero: primer complejo en finalizar sus obras, con clara orientación al segmento de departamentos premium (el más reducido en Dolfínes posee 155 metros cuadrados). En su momento fueron promocionadas como las más altas de Rosario ( $\mathrm{y}$ del interior de Argentina, título que mantienen a la fecha). Las oficinas de Nordlink fueron la vanguardia en oficinas de alta gama sobre la zona ribereña, pensadas para "incentivar la creatividad de sus ejecutivos y empleados a través de una nueva distribución, servicios y la complicidad de un entorno motivador". A la fecha no se dispone de pautas publicitarias pero el desarrollo mantiene una imagen comercial como el único complejo inmobiliario finalizado de la zona.

- UG6. Maui: "Si resultaba difícil imaginar una isla caribeña en pleno litoral rosarino, ahora es casi una realidad", refería Clarín Arquitectura (Ercolano, 2014). Orientado a jóvenes, familias y parejas de clase alta. El complejo motorizado por Servicios Portuarios S.A. tiene una frecuencia publicitaria intermedia (cada 15 días o mensual). Con mensajes como "el proyecto inmobiliario más innovador de Rosario", "rodeado de naturaleza y unas increíbles vistas a la ciudad y al río, este proyecto es icono de diseño y arquitectura para la ciudad" o "para vivir como en un resort cinco estrellas". Una estrategia destacada en la comunicación de ventas del emprendimiento es el showroom 3D que muestra los potenciales habitantes del desarrollo urbanístico cómo quedarán las unidades una vez terminado el complejo.

- M. 407. Condominios del Alto: con su variada oferta de departamentos, dúplex, viviendas en altura, oficinas, amenities y locales comerciales, sus estrategias promocionales están enfocadas a un público de clase media y media-alta con predominio de familias. Sus comunicaciones tienen una alta frecuencia de aparición (semanal) en páginas inmobiliarias, y mensual en 
revistas como Mercado Inmobiliario (edición impresa). Algunas de sus frases de choque resaltan la idea de que "cada día son más los que eligen vivir cerca del río, cerca del centro, en medio de un paisaje urbano diferente" y "verde, relax, seguridad, jerarquía, diseño, todo el aire y tu ciudad". Los mensajes promueven recurrentemente la idea de un verdadero "hogar, dulce, cómodo, amplio, cerca de todo, hogar" con una oferta combinada de amenities, seguridad, privacidad y compromiso ecológico.

\section{Figura 4. Publicidades gráficas de las distintas Unidades de Gestión} en Puerto Norte Rosario

\section{LO IMPOSIBLE SE CONSIGUE EN CUOTAS. LO IMPOSIBLE SE CONSIGUE EN CUOTAS EN PESOS. LO IMPOSIBLE SE CONSIGUE EN CUOTAS EN PESOS A DIEZ AÑOS. LO IMPOSIBLE SE CONSIGUE EN CUOTAS EN PESOS A DIEZ AÑOS EN PUERTO NORTE.}

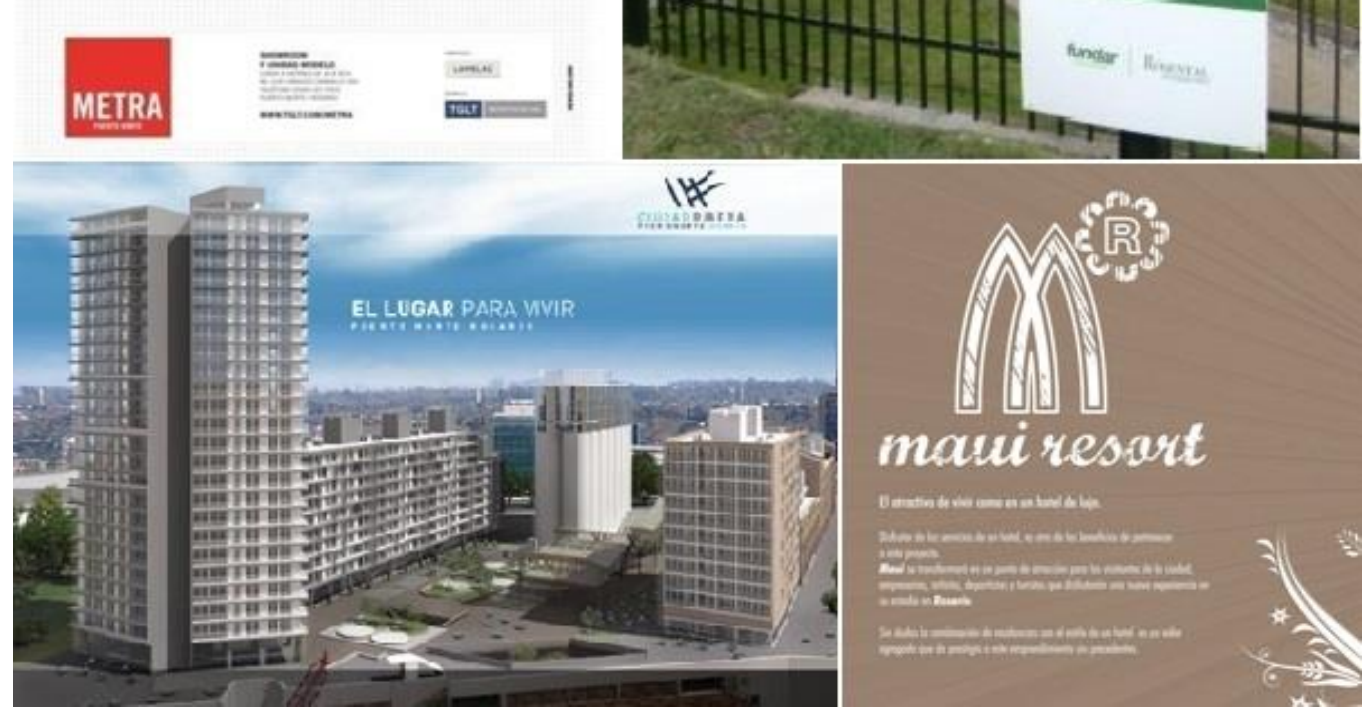

Fuente: Desarrolladoras inmobiliarias, 2015.

Más allá de los recursos utilizados en las comunicaciones de venta de los diferentes emprendimientos, es ostensible la presencia de un modelo de comunicación que mantiene las premisas básicas de los modelos canónicos. 
Estos implican una fuerte presencia de quien emite los mensajes (los grupos y consorcios desarrolladores), tanto en las publicidades y promociones de los proyectos como en la imagen de marca que se promueve en cada caso; y las decisiones publicitarias que llevan a tomar canales preferenciales (anuncios web, revistas del mercado inmobiliario, medios especializados en arquitectura, etc.) para difundir los avisos y notas de prensa.

Luego, los receptores (potenciales compradores o interesados en los bienes puestos a su consideración) serán quienes canalizarán sus expectativas y generarán los "efectos deseados" de las comunicaciones de venta, traducido esto en los resultados revelados por los propios desarrolladores en cuanto a las operaciones concretadas.

\section{Conclusión}

En la última década, Rosario fue una de las ciudades con mayor crecimiento económico de Argentina, demandando diferentes espacios para intervenciones urbanas. En este contexto, Puerto Norte se propone como una nueva centralidad, en un área estratégica, que poseía grandes lotes vacantes pertenecientes al antiguo puerto y sector del ferrocarril, factibles para un nuevo desarrollo. El gran proyecto urbano se orienta a residencias, comercios, oficinas y entretenimientos con infraestructura y servicios de alto nivel, para usuarios e inversores tanto de carácter local como internacional, sin considerar espacios destinados a dar servicios especiales (educativos y de salud). El perfil urbano de la costa rosarina se modifica, en donde dicha reconversión urbana es entendida como un enclave a escala regional.

La comercialización se presenta en forma variada: en los departamentos pequeños y locales comerciales es alta, en los departamentos grandes es intermedia y en las oficinas muestra otra dinámica. Además, no ha sido uniforme en todo el período: las nuevas demandas generan modificaciones de los mercados y la incorporación de otros. En otras palabras, el sector exclusivo al cual se orienta la venta al principio, es un fragmento reducido y debido a esto el mercado se 
fracciona en unidades de menores superficies orientado hacia una clase media en los últimos años. Sin embargo, la vivienda para clases sociales medias-bajas sigue ausente en todas las Unidades de Gestión analizadas en este trabajo.

La oferta inmobiliaria maneja diferentes dispositivos publicitarios que pueden ser claramente identificados, a partir del análisis de la construcción discursiva de las pautas publicitarias que los desarrolladores proponen a sus públicos. Allí se identifica el establecimiento de un contrato de lectura (Verón, 1985) en el que las interacciones simbólicas y las interpretaciones de mensajes se dan en el marco de la sedimentación de un modelo de ciudad que incluso intenta ser internacional, y de una concepción de estilo de vida que contempla o prevé percepciones interpretativas y juicios estéticos por parte de receptores que no pueden sino "elegir" ese proyecto. Este se trata del mejor y más adecuado en un contexto mediático general que produce un ambiente, una especie de capilaridad simbólica, por la cual el sentido discurre.

Los espacios cerrados que se ofertan en las estrategias de marketing muestran cómo (al igual que en muchas otras ciudades latinoamericanas, donde las tipologías de los desarrollos toman nombres como "barrios privados y clubes de campo", en la periferia, o "torres jardín", en áreas centrales) se alimenta una filosofía de la exclusividad, la seguridad, la calidad ambiental o el confort, proponiendo productos diferenciados según tácticas publicitarias específicas acorde a la coyuntura económica del momento.

La retórica publicitaria exhibe a estos proyectos urbanísticos como bienes de consumo que se ofrecen como cualquier otro en los medios de comunicación, y postulan a un potencial comprador que reúne capacidad de compra y posibilidades de elegir. Esto siempre sucede dentro de los parámetros que acotan y restringen la oferta a determinados valores y representaciones vinculadas con un estilo de vida específico de los sectores altos y medios-altos, a los que se alude en los mensajes publicitarios y comunicaciones de venta.

En suma, el marketing urbano propone formas de mirar una realidad no solo territorial sino también política, económica y social, pudiendo alterar las 
representaciones y modelos de una "ciudad posible". $Y$ en este sentido, la propuesta urbanística de Puerto Norte refleja una sociedad rosarina que no logra integrar socialmente (en el caso que nos ocupa, a través de la vivienda) a los distintos sectores poblaciones de la ciudad, a la par que los mensajes publicitarios "naturalizan" una segregación socioespacial basada en un consumismo que se articula principalmente sobre valores y procesos identitarios asociados a lo "exclusivo".

\section{Referencias bibliográficas}

Barenboim, C. A. (2010). Dinámica inmobiliaria en la ciudad de Rosario (Período 1998 - 2009). Proyección (8), 1-25.

Barenboim, C. A. (2013). Mercado de suelo y su ordenamiento en la periferia de las ciudades. El caso de Rosario, Argentina. Buenos Aires: Editorial Teseo.

Barenboim, C. A. (2014). Evolución de la costa central y su vinculación con el gran proyecto urbano de Puerto Norte en la ciudad de Rosario. Revista Iberoamericana de Estudios Municipales (10), 61-82.

Barenboim, C. A. (2015). Procesos de producción, uso y valorización inmobiliaria del gran proyecto urbano Puerto Norte en la ciudad de Rosario, Argentina. En VII Seminario Internacional de Investigación en Urbanismo, (pp. 1-13). Barcelona: DUOT.

Cuenya, B. (2012). Grandes proyectos urbanos, cambios de centralidad urbana y conflicto de intereses. Notas sobre la experiencia argentina. En Cuenya, B. et al. (comps.), Grandes Proyectos Urbanos. Miradas críticas sobre la experiencia argentina y brasilera (pp. 27-66). Buenos Aires: Café de las ciudades.

Cuenya, B. et al. (2009). Movilización de plusvalías en un gran proyecto urbano. La experiencia de Puerto Norte en la ciudad de Rosario, Argentina. Rosario: Lincoln Institute.

Decima, J. (2012, 29 de Julio).¿Cuánto cuesta un departamento de alta gama? Diario Rosarionet, p.5. 
Desarrolladoras Inmobiliarias. (2015). Publicidades de las distintas Unidades de Gestión .Rosario: editoriales inmobiliarias. Recuperado de www.metrapuertonorte.com, www.tglt.com/Forum, www.ciudadribera.com, www.dolfines.com, ww.maui.com.ar y www.condominiosdelalto.com.

Dirección General del Plan Director.(2011). Plan Urbano Rosario 2007 - 2017. Rosario: Secretaria de Planeamiento de la Municipalidad de Rosario.

Ercolano, C. (2014). Suplemento Clarín Arquitectura. Buenos Aires: Clarín. Recuperado de www.arq.clarin.com/inmobiliario/distinto_0_1074493085.html. Harvey, D. (2007). Breve historia del neoliberalismo. Madrid: Akal.

Hellín Ortuño, P. y Fernández Rincón, A. (2014). Los mecanismos discursivos de la publicidad inmobiliaria. En El Foro 2014, (pp. 1-14). Vigo: Universidad de Vigo. Recuperado de www.foro2014.com/wp-content/uploads/2014/02/50.Hell\%C3\%ADn-Ortu\%C3\%B1o-Fernandez-Rinc\%C3\%B3n.pdf.

Janoschka, M. (2002). El nuevo modelo de la ciudad latinoamericana: fragmentación y privatización. En Revista EURE, 28 (85),11-29.

Martinis, I. (2011). Experiencias de renovación urbana y relocalización. El caso del barrio Las Malvinas (Rosario, Santa Fe). Tesis de Licenciatura en Trabajo Social. Rosario: Universidad Nacional de Rosario.

Mejía Escalante, M.(2009). Del discurso inmobiliario a la habitabilidad del espacio residencial. En Torres, Carlos; Revista Bitácora Urbano Territorial, 1 (4), 45-58.

Ortolá Martínez, G. (2013). Marketing para desarrollos inmobiliarios. Creando Real Estate con valor agregado. Buenos Aires: Bienes Raíces Ediciones.

Ortega Carrillo et al. (2011). Publicidad, educación y nuevas tecnologías. En Gobierno de España Instituto de Tecnologías Educativas. Madrid: Gobierno de España.

Ramírez Bayardi, J. (2012). La Comunicación Externa en una Organización: Análisis descriptivo de las herramientas de comunicación y públicos externos (Bauen Pilay). Tesis de Licenciatura en Relaciones Públicas. Rosario: Universidad Abierta Interamericana.

Scheinsohn, D. (2009). Comunicación Estratégica. Buenos Aires: Granica S.A. 
Sica, T. (2014). Impulsos Negocios Noticas de Rosario. Rosario: Impulsos Negocios.

Verón, E. (1985). El análisis del Contrato de Lectura, un nuevo método para los estudios de posicionamiento de los soportes de los media. En Les Medias: Experiences, recherchesactuelles, aplications (pp.1-14). París: IREP.

Entrevista realizada al presidente de la Federación Inmobiliaria Argentina y Colegio de Corredores Inmobiliarios de Santa Fe Arq. Javier Grandinetti. Rosario, 02/04/15.

Entrevista realizada a la Coordinadora del Programa de Equilibrios Centro Periferia de la Secretaria de Planeamiento Arq. Cecilia Martínez. Rosario, 17/09/14.

\section{Para citar este artículo:}

Barenboim, C., y Tomino, G. (2016). Estrategias de comercialización y marketing urbano: el producto de Puerto Norte Rosario, Argentina. Collectivus, Revista de Ciencias Sociales, 3(1), 66-90. doi: http://dx.doi.org/10.15648/Coll.1.2016.4 